\title{
Anaemia is an essential complication of ANCA-associated renal vasculitis: a single center cohort study
}

Tetsuya Kawamura', Joichi Usui ${ }^{1 *}$ D, Shuzo Kaneko ${ }^{1}$, Ryoya Tsunoda', Eri Imai ${ }^{1}$, Hirayasu Kai ${ }^{1}$, Naoki Morito', Chie Saito ${ }^{1}$, Michio Nagata ${ }^{2}$ and Kunihiro Yamagata ${ }^{1}$

\begin{abstract}
Background: Anaemia is a common complication of patients with antineutrophil cytoplasmic antibody (ANCA)associated renal vasculitis. Nevertheless, the cause and degree of such cases of anaemia have not been elucidated in detail. We aimed to investigate the prevalence, cause, pathogenesis of anaemia and the impact of anaemia on prognosis in patients with ANCA-associated renal vasculitis.

Methods: We identified 45 patients with ANCA-associated renal vasculitis that were clinically and/or histologically diagnosed and treated from 2003 to 2014 at University of Tsukuba Hospital. The relationships between anaemia and various clinicopathological findings were evaluated.

Results: At the time of diagnosis of ANCA-associated renal vasculitis, all patients showed anaemia, with a mean haemoglobin level of $7.5 \pm 1.3 \mathrm{~g} / \mathrm{dL}$. Renal anaemia was diagnosed in $92 \%$ of patients, anaemia of chronic disease (ACD) in 56\%, and anaemia due to hemorrhage in 20\%. Next, the patients were divided into two groups according to anaemia severity: minimum haemoglobin $(\operatorname{min~Hb})<7.5(n=24)$ and $\min \mathrm{Hb} \geq 7.5(n=21)$. A comparison of baseline characteristics showed that serum albumin, maximum serum creatinine, minimum estimated glomerular filtration rate (eGFR), serum cystatin $C$, and the area of tubulointerstitial damage were significantly different between the haemoglobin groups $(p<0.05)$. No significant intergroup differences were observed in iron-related or inflammation-related data. With regard to the relationship between anaemia severity and prognosis, patients in the min $\mathrm{Hb}<7.5$ group tended to have a lower eGFR. Anaemia severity was associated with markedly lower survival (Log-rank test, $p=0.03$ ).

Conclusions: In this cohort of patients with ANCA-associated renal vasculitis, all subjects exhibited anaemia. In regard to the cause and pathogenesis, the most prevalent form of anaemia was renal anaemia, not ACD, and a potential reason for the high prevalence of anaemia in our cohort may have been the interaction between renal anaemia and ACD. Moreover, anaemia severity was significantly associated with the degree of renal dysfunction and life prognosis.
\end{abstract}

Keywords: Anaemia of chronic disease, Renal anaemia, ANCA-associated renal vasculitis

\footnotetext{
* Correspondence: j-usui@md.tsukuba.ac.jp

'Department of Nephrology, Faculty of Medicine, University of Tsukuba, 1-1-1

Tennodai, Tsukuba, Ibaraki 305-8575, Japan

Full list of author information is available at the end of the article
} 


\section{Background}

Antineutrophil cytoplasmic antibody (ANCA)-associated renal vasculitis is a systemic autoimmune disease characterized by pauci-immune-type necrotizing smallvessel vasculitis; vessels in the kidney, skin, respiratory tract, gastrointestinal tract, and peripheral nerves are often involved. Patients with ANCA-associated renal vasculitis may present with a variety of clinical manifestations, such as fatigue, fever, and weight loss [1]. Although routine laboratory tests are generally nonspecific for ANCA-associated renal vasculitis, common laboratory findings in ANCA-associated renal vasculitis include leukocytosis, thrombocytosis, normochromic and normocytic anaemia, and the elevation of acutephase inflammatory proteins. For example, a previous study reported that anaemia was seen in $73 \%$ of patients with granulomatosis with polyangiitis (GPA) and the mean haemoglobin was $11.1 \mathrm{~g} / \mathrm{dL}$ (range, 5.0$15.1 \mathrm{~g} / \mathrm{dL}$ ) before treatment initiation [2]. In another study, 14/36 (39\%) of GPA patients with remission status presented with anaemia, and the mean haemoglobin was $13.0 \pm 2.1 \mathrm{~g} / \mathrm{dl}$ [3]. Thus, anaemia is known to be a common complication of patients with ANCAassociated renal vasculitis.

Anaemia has also been reported as a complication in other autoimmune inflammatory diseases, such as rheumatoid arthritis [4], inflammatory bowel disease [5, 6] and systemic lupus erythematosus (SLE) [7]. Anaemia that occurs as a complication in these diseases is generally known as anaemia of chronic disease (ACD; also called anaemia of inflammation) [8]. The mechanisms of ACD are thought to be hepcidin-induced changes in iron metabolism, inadequate response of erythropoiesis, and shortening of the erythrocyte lifespan. A number of serious conditions are associated with ACD, including infections, malignancies, autoimmune diseases, chronic rejection after transplantation, and chronic kidney disease (CKD). ACD is automatically presumed to be complicated with ANCAassociated renal vasculitis, and the causes of anaemia with ANCA-associated renal vasculitis are expected to be multifactorial. These causes can include renal dysfunction, alveolar haemorrhage, malnutrition, the use of immunosuppressive drugs, frequent in-hospital phlebotomies and iron deficiency. However, the associations among these factors and the severity of anaemia in patients with ANCA-associated renal vasculitis have not been elucidated in detail. Moreover, almost all previous studies of anaemia in association with other autoimmune inflammatory diseases excluded patients with renal dysfunction. Therefore, the pathogenesis and severity of anaemia in patients with ANCA-associated renal vasculitis may differ from those of anaemia in patients with other autoimmune inflammatory diseases.
In general, anaemia in elderly patients is closely associated with various poor outcomes such as hospitalization and mortality [9]. In patients with heart failure, anaemia is associated with increased mortality [10]. Additionally, in patients with CKD, several studies have demonstrated that anaemia is closely related to mortality and the progression of renal failure [11, 12]. Therefore, the combination of severe anaemia and ANCA-associated renal vasculitis may lead to poor renal prognosis and shortened lifespan.

In the present study, we aimed to investigate the prevalence and pathogenesis of anaemia in patients with ANCA-associated renal vasculitis. We also evaluated the pathological findings and the impact of anaemia on the renal and life prognoses of the patients.

\section{Methods}

\section{Study population}

We identified 45 patients with ANCA-associated renal vasculitis who had been clinically and/or histologically diagnosed and treated from 2003 to 2014 at University of Tsukuba Hospital. We recorded the demographic, clinical and pathological features of these cases as well as the treatments, patient survival rates and renal outcomes. This research complied with the Declaration of Helsinki and was approved by the Ethics Committee of University of Tsukuba Hospital (H20-273, H24-169 and H26-175). All participants provided informed consent to participate in the study as required by the Institutional Review Board (H20-273). An announcement of this study was simultaneously posted at the outpatient clinic of our institute.

\section{Definition of anaemia}

According to the World Health Organization, anaemia is defined by haemoglobin levels lower than $13.0 \mathrm{~g} / \mathrm{dL}$ for men and $12.0 \mathrm{~g} / \mathrm{dL}$ for women [13]. Renal anaemia is defined as the presence of anaemia in association with a relatively low erythropoietin concentration $(<50 \mathrm{mIU} /$ $\mathrm{mL}$ ) or with a low estimated glomerular filtration rate (eGFR) $\left(<30 \mathrm{~min} / \mathrm{mL} / 1.73 \mathrm{~m}^{2}\right)$ but without an increase in the reticulocyte count $\left(<10 \times 10^{4} / \mu \mathrm{L}\right)[14,15]$. The definition of ACD requires a low transferrin saturation $(<16 \%)$ with a normal or increased serum ferritin concentration $(>100 \mathrm{ng} / \mathrm{mL}$ ). Iron-deficiency anaemia is characterized by the presence of anaemia in association with low serum ferritin $(<10 \mathrm{ng} / \mathrm{mL}$ for females, $<15 \mathrm{ng} /$ $\mathrm{mL}$ for males) or with a transferrin saturation of less than $16 \%$ together with a serum ferritin level of less than $30 \mathrm{ng} /$ $\mathrm{mL}$. The combination of iron-deficiency anaemia and ACD is characterized by a transferrin saturation of less than $16 \%$ and a serum ferritin between 30 and $100 \mathrm{ng} / \mathrm{mL}$ inclusive $[6,8]$. Moreover, in the present study, we evaluated the serum hepcidin- 25 concentration to use as a reference 
value for $\mathrm{ACD}$. The serum hepcidin-25 concentration was measured using a commercially available enzyme-linked immunosorbent assay (ELISA) kit (product No. S-1337; Peninsula Laboratories, Bachem, CA). This ELISA system was used in a number of previous studies [16, 17]. If patients had additional cytopenia (white blood cell count < $4000 / \mu \mathrm{L}$, platelet count $<10 \times 10^{4} / \mu \mathrm{L}$ ) and/or abnormal white blood cell differentiation, haematological abnormalities were suspected and we added a haematological examination, including bone marrow aspiration. Haemolysis was diagnosed if the lactate dehydrogenase level was greater than $500 \mathrm{IU} / \mathrm{L}$ without the elevation of another liver enzyme or if the haptoglobin level was less than $10 \mathrm{mg} / \mathrm{dL}$. Vitamin B12 deficiency was diagnosed if the serum vitamin B12 concentration was less than $200 \mathrm{pg} / \mathrm{mL}$, and folate deficiency was diagnosed if the serum folate level was less than $3.6 \mathrm{ng} / \mathrm{mL}$.

\section{Pathologic analysis}

Renal biopsy specimens were routinely assessed by light microscopy, immunofluorescence, and electron microscopy.
An expert renal pathologist made the diagnoses according to the international histological classification [18]. The area of tubulointerstitial damage was semi-quantitatively evaluated in renal cortical tissue [19-21].

\section{Statistical analysis}

The laboratory examination results were summarized in the form of percentages, means \pm standard deviations (SD), or medians with ranges. To perform statistical comparisons, we used the chi-squared test for categorical variables and Student's $t$-test or the Mann-Whitney U test for continuous variables. The cumulative survival and renal survival were estimated using the Kaplan-Meier method and compared among the groups using the log-rank test. A $p$ value $<0.05$ was considered statistically significant in all analyses. The IBM SPSS software package, ver. 22, was used.

\section{Results}

\section{Patient characteristics at diagnosis}

The patient characteristics at diagnosis are shown in Table 1 . Of the 45 patients, $20(44 \%)$ were men. The

Table 1 Clinicopathological findings of patients with ANCA-associated renal vasculitis in each anaemia severity group

\begin{tabular}{|c|c|c|c|c|}
\hline Variable & All patients & Min $\mathrm{Hb}<7.5$ & $\mathrm{Min} \mathrm{Hb} \geq 7.5$ & $P$ Value \\
\hline Patient number & 45 & 24 & 21 & \\
\hline Gender male:female & $20: 25$ & $12: 12$ & $8: 13$ & 0.42 \\
\hline Age (years) & $71 \pm 7.8(47-82)$ & $72 \pm 7.0(54-82)$ & $70 \pm 8.7(47-82)$ & 0.36 \\
\hline Birmingham vasculitis activity score & $20(12-39)$ & $19(12-36)$ & $20(12-39)$ & 0.58 \\
\hline Haemoglobin on admission ( $\mathrm{g} / \mathrm{dL})$ & $9.0 \pm 1.6$ & $8.1 \pm 1.1$ & $10.1 \pm 1.3$ & $<0.001$ \\
\hline Minimum haemoglobin (g/dL) & $7.5 \pm 1.3$ & $6.5 \pm 0.6$ & $8.7 \pm 0.9$ & $<0.001$ \\
\hline MCV (fL) & $90 \pm 6.2$ & $88 \pm 6.8$ & $91 \pm 5.1$ & 0.18 \\
\hline $\mathrm{MCH}(\mathrm{pg})$ & $29.5 \pm 2.4$ & $29.1 \pm 2.6$ & $30.0 \pm 2.2$ & 0.21 \\
\hline MCHC (\%) & $33.0 \pm 1.2$ & $32.9 \pm 0.9$ & $33.0 \pm 1.3$ & 0.76 \\
\hline Reticulocyte count $\left(\times 10^{4} / \mu \mathrm{L}\right)$ & $4.65 \pm 2.50$ & $4.23 \pm 2.47$ & $5.09 \pm 2.54$ & 0.35 \\
\hline Serum erythropoietin $(\mathrm{mlU} / \mathrm{mL})$ & $15.1(5.8-105)$ & $17.5(5.8-105)$ & $14.5(11-36.6)$ & 0.43 \\
\hline Transferrin saturation (\%) & $14.7(4.2-80.2)$ & $12.8(4.2-80.2)$ & $17.5(9.7-54.5)$ & 0.18 \\
\hline Serum ferritin $(\mathrm{ng} / \mathrm{mL})$ & $322(46.9-2231)$ & $382(46.9-1839)$ & $291(94.9-2231)$ & 0.21 \\
\hline Serum c-reactive protein (mg/dL) & $6.8(0.03-24.5)$ & $7.9(0.43-24.5)$ & $5.0(0.03-17.3)$ & 0.09 \\
\hline Serum hepcidin-25 (ng/mL) & $71.5(10.5-463)$ & $74.9(45.9-463)$ & $37(10.5-363)$ & 0.28 \\
\hline Serum albumin $(g / d L)$ & $2.6 \pm 0.8$ & $2.3 \pm 0.6$ & $2.9 \pm 0.8$ & 0.004 \\
\hline Serum creatinine on admission (mg/dL) & $2.5(1.0-10.8$ & $2.9(1.0-10.8)$ & $2.3(1.0-6.3)$ & 0.06 \\
\hline Maximum serum creatinine $(\mathrm{mg} / \mathrm{dL})$ & $3.2(1.0-11.7)$ & $4.4(1.1-11.7)$ & $2.4(1.0-7.2)$ & 0.01 \\
\hline eGFR on admission $\left(\mathrm{mL} / \mathrm{min} / 1.73 \mathrm{~m}^{2}\right)$ & $19.5(4.2-54.2)$ & $13.8(4.2-44.6)$ & $21.6(7.0-54.2)$ & 0.09 \\
\hline Minimum eGFR (mL/min/1.73 m²) & $15.3(3.9-54.2)$ & $8.9(3.9-39.2)$ & $19.0(4.8-54.2)$ & 0.01 \\
\hline Blood urea nitrogen $(\mathrm{mg} / \mathrm{dL})$ & $34.5(13-101)$ & $36.9(13-101)$ & $30.9(18.3-62)$ & 0.09 \\
\hline Serum cystatin c (mg/L) & $2.8 \pm 0.9$ & $3.2 \pm 0.9$ & $2.2 \pm 0.6$ & 0.02 \\
\hline Number of renal biopsy, n (\%) & $33(73)$ & $13(54)$ & $20(95)$ & 0.00 \\
\hline Area of tubulointerstitial damage (\%) & $55 \pm 21$ & $65 \pm 18$ & $48 \pm 20$ & 0.048 \\
\hline
\end{tabular}

Values are shown as the numbers of patients, the median (range) or the mean \pm SD. Abbreviations: Min Hb Minimum haemoglobin, MCV Mean corpuscular volume, MCH Mean corpuscular haemoglobin, MCHC Mean corpuscular haemoglobin concentration, eGFR Estimated glomerular filtration rate 
mean age at diagnosis was $71 \pm 7.8$ years. Two patients already had renal dysfunction and 8 patients showed mild anaemia (haemoglobin 10.1-12.9 g/dL) before the disease onset. Eighteen patients had a history of hypertension, 2 had a history of diabetes, 3 had a history of cardiovascular disease, 4 had a history of malignancy, and 1 patient had a history of rheumatoid arthritis. In this cohort, the median follow-up duration was 42 months (range, 0-123 months). All patients were myeloperoxidase-ANCA single-positive. With respect to the vasculitis disease classification, physicians diagnosed microscopic polyangiitis in 43 patients, eosinophilic granulomatosis with polyangiitis in 1 patient, and GPA in 1 patient. The median Birmingham Vasculitis Activity Score was 20. The mean haemoglobin on admission was $9.0 \mathrm{~g} / \mathrm{dL}$, and the mean minimum haemoglobin ( $\mathrm{min}$ $\mathrm{Hb}$ ) was $7.5 \mathrm{~g} / \mathrm{dL}$. The median serum erythropoietin was $15.1 \mathrm{mIU} / \mathrm{mL}$ (based on measurement in 25 patients), the median serum ferritin was $322 \mathrm{ng} / \mathrm{mL}$, the median serum c-reactive protein was $6.8 \mathrm{mg} / \mathrm{dL}$, the median serum hepcidin- 25 was $71.5 \mathrm{ng} / \mathrm{mL}$ (based on measurement in 15 patients) and the median minimum eGFR was $15.3 \mathrm{~mL} / \mathrm{min} / 1.73 \mathrm{~m}^{2}$ (range, $3.9-54.2 \mathrm{~mL} / \mathrm{min} /$ $1.73 \mathrm{~m}^{2}$ ). All patients had renal involvement, and 33 patients $(73 \%)$ had undergone renal biopsy. Using the international histological classification [18], we identified 8 patients in the Focal class, 12 in the Crescentic class, 7 in the Mixed class, and 2 in the Sclerotic class. In 4 patients, the renal biopsy specimens were inadequate for pathological diagnosis. The mean area of tubulointerstitial damage was $55 \%$. Twenty-three patients $(51 \%)$ had pulmonary involvement, including 20 with interstitial pneumonia, 5 with alveolar haemorrhage, and 2 with pulmonary granuloma.

\section{Prevalence and pathogenesis of anaemia with ANCA- associated renal vasculitis.}

In this study, we focused on the relationship between ANCA-associated renal vasculitis and anaemia. At the time of the diagnosis of ANCA-associated renal vasculitis, all patients showed anaemia (the haemoglobin on admission was $9.0 \pm 1.6 \mathrm{~g} / \mathrm{dL}$ and the min $\mathrm{Hb}$ was $7.5 \pm$ $1.3 \mathrm{~g} / \mathrm{dL}$ ). Age and gender had no significant influence on the severity of anaemia. The causes of anaemia are summarized in Fig. 1. Renal anaemia was diagnosed in 35 of 38 (92\%) patients, ACD was diagnosed in 20 of 36 (56\%) patients (one patient was diagnosed with irondeficiency anaemia-associated ACD), and anaemia due to haemorrhage was diagnosed in 9 of $45(20 \%)$ patients. No patients were suspected to exhibit haematological abnormalities or haemolysis. Vitamin B12 deficiency was diagnosed in 1 of 15 (7\%) patients, and folate deficiency was diagnosed in 6 of 11 (55\%) patients. However, none of the patients exhibited macrocytic anaemia, and none

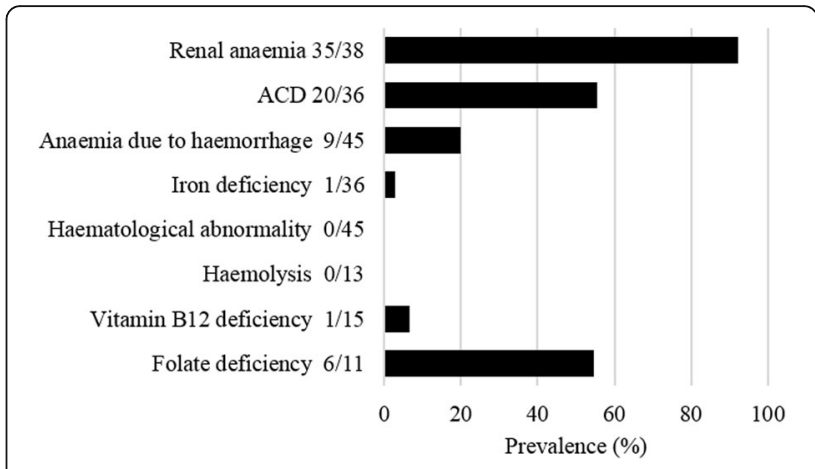

Fig. 1 The causes of anaemia in patients with ANCA-associated renal vasculitis. Abbreviation: ACD, anaemia of chronic disease

required vitamin $\mathrm{B} 12$ or folate supplementation. Therefore, we considered that vitamin B12 and folate deficiency did not greatly affect the anaemia severity.

\section{Comparison of backgrounds and prognosis according to anaemia severity}

Next, we investigated the features of the patients that were influenced by the anaemia severity. The patients were divided into two groups according to their min $\mathrm{Hb}$ values: a group with min $\mathrm{Hb}<7.5(n=24)$ and a group with min $\mathrm{Hb} \geq 7.5(n=21)$ (Table 1$)$. A comparison of the baseline characteristics showed that serum albumin, maximum serum creatinine, minimum eGFR, serum cystatin $C$, and the area of tubulointerstitial damage were significantly different between the two groups. No significant intergroup differences were observed in ironrelated data such as transferrin saturation and serum ferritin, or in inflammation-related data such as serum ferritin, serum c-reactive protein, and serum hepcidin- 25 .

Next, a comparison of the treatments and prognoses is shown in Table 2. Not surprisingly, the transfusion of red blood cells and the use of erythropoiesisstimulating agents (ESAs) were more frequent in the min $\mathrm{Hb}<7.5$ group than the min $\mathrm{Hb} \geq 7.5$ group. Of the treatments used for ANCA-associated renal vasculitis, plasma exchange therapy was chosen significantly more often in the min $\mathrm{Hb}<7.5$ group than in the min $\mathrm{Hb} \geq 7.5$ group. The indication for plasma exchange therapy in these 6 patients was alveolar haemorrhage in 3 patients and severe renal involvement in 3 patients. Three out of 5 patients with alveolar haemorrhage were treated with plasma exchange. One of the remaining 2 patients was not treated with plasma exchange because the alveolar haemorrhage was considered to be resolved. Although we reviewed the relevant medical records, we could not determine why the other patient was treated without plasma exchange. By contrast, the rates of treatment with steroid pulse therapy and of treatment using cyclophosphamide at 4 and 
Table 2 Comparison of treatments and prognoses

\begin{tabular}{|c|c|c|c|c|}
\hline & All patients & $\mathrm{Min} \mathrm{Hb}<7.5$ & Min $\mathrm{Hb} \geq 7.5$ & $P$ Value \\
\hline \multicolumn{5}{|l|}{ Treatment } \\
\hline Blood transfusion of RBC, $n(\%)$ & $13(29)$ & $12(50)$ & $1(5)$ & 0.001 \\
\hline Use of ESAs, $n(\%)$ & $20(44)$ & $16(67)$ & $4(19)$ & 0.001 \\
\hline Plasma exchange therapy, $n$ (\%) & $6(13)$ & $6(25)$ & $0(0)$ & 0.01 \\
\hline Steroid pulse therapy, $n(\%)$ & $20(44)$ & $13(54)$ & $7(33)$ & 0.16 \\
\hline Use of $\mathrm{CY}$ within 4 weeks after treatment initiation, $n(\%)$ & $1(2)$ & $1(4)$ & $0(0)$ & 0.33 \\
\hline Use of CY within 12 weeks after treatment initiation, $n(\%)$ & $14(35)$ & $9(47)$ & $5(24)$ & 0.12 \\
\hline \multicolumn{5}{|l|}{ Prognosis } \\
\hline Duration of hospitalization (days) & $70 \pm 26$ & $75 \pm 28$ & $65 \pm 23$ & 0.23 \\
\hline Number of deaths during the first hospitalization, $n(\%)$ & $4(9)$ & $4(17)$ & $0(0)$ & 0.05 \\
\hline Number of deaths at last follow-up, $n(\%)$ & $11(24)$ & $8(33)$ & $3(14)$ & 0.14 \\
\hline Number of patients with end-stage kidney disease at last follow-up, $n(\%)$ & $2(4)$ & $2(8)$ & $0(0)$ & 0.18 \\
\hline
\end{tabular}

Values are shown as the numbers of patients or the mean \pm SD. Abbreviations: Min Hb Minimum haemoglobin, RBC Red blood cell, ESAs Erythropoiesis-stimulating agents, CY Cyclophosphamide

12 weeks after treatment initiation were similar between the two groups.

Finally, we examined the relationship between the severity of anaemia and prognosis (Table 2). There was no significant difference in the duration of hospitalization. However, all 4 patients who died during the first hospitalization were in the $\min \mathrm{Hb}<7.5$ group. Over the course of the follow-up, 11 of 45 (24\%) patients died, and 2 of 45 (4\%) patients developed end-stage kidney disease. Figures 2 and 3 show the temporal changes in the haemoglobin concentration and eGFR levels. The haemoglobin concentration showed significant differences between the groups upon admission, at the time of $\min \mathrm{Hb}$, after 2 weeks, and after 48 weeks. There is a possibility that severe anaemia at diagnosis was prolonged for at least 1 year after the diagnosis. On the other hand, eGFR showed significant differences between the groups at the time of minimum eGFR, and the $\min \mathrm{Hb}<7.5$ group tended to have a lower eGFR.

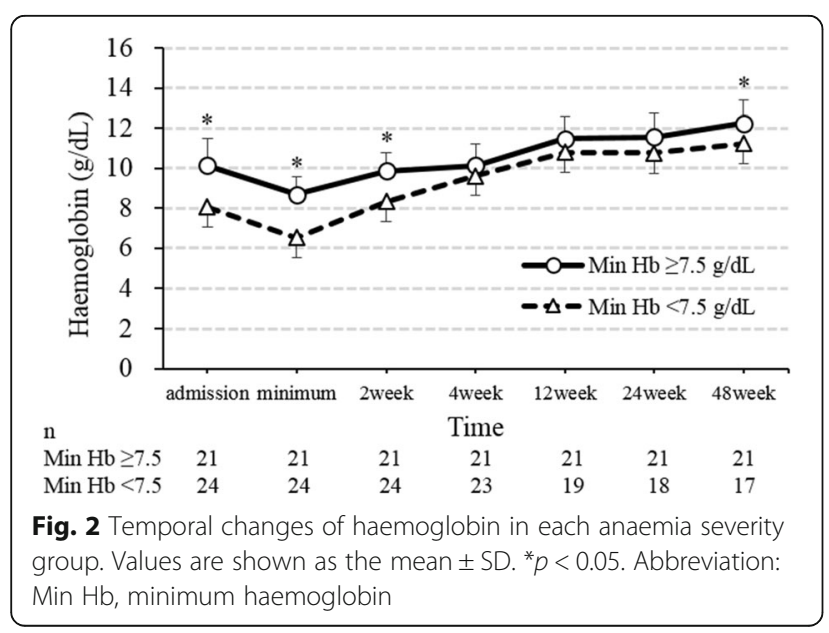

As shown in the survival curve estimated using the Kaplan-Meier method (Fig. 4), increased anaemia severity was associated with a markedly lower survival rate.

\section{Discussion}

In the present study, we focused on the physiological impact of anaemia in cases of ANCA-associated renal vasculitis. All ANCA-associated renal vasculitis patients in this cohort were found to have anaemia, and the causes of anaemia in our patients were expected to be multifactorial, with renal anaemia being the predominant type. Also, the severity of anaemia was closely associated with renal function, but not with the iron-related or inflammation-related findings. Moreover, anaemia severity was a factor affecting the renal and life prognoses of ANCA-associated renal vasculitis patients.

Before discussing our findings, we should first consider the previous studies on anaemia in patients with other

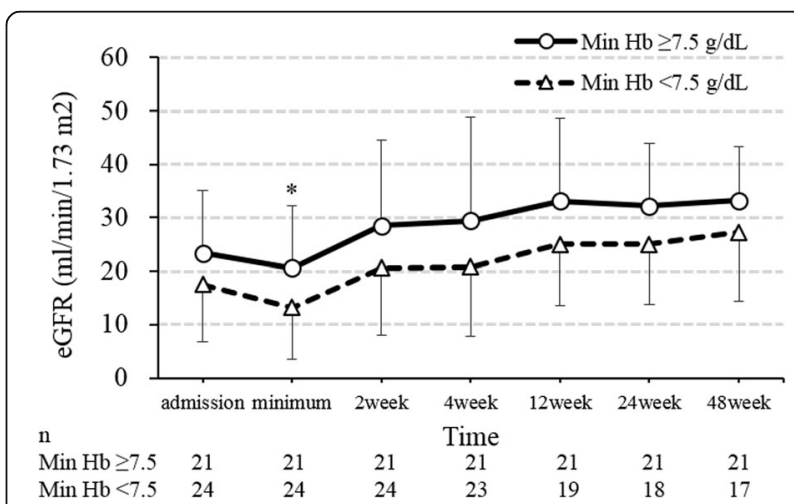

Fig. 3 Temporal changes of eGFR in each anaemia severity group. Values are shown as the mean $\pm \mathrm{SD} .{ }^{*} p<0.05$. Abbreviations: $\mathrm{Min} \mathrm{Hb}$, minimum haemoglobin; eGFR, estimated glomerular filtration rate 


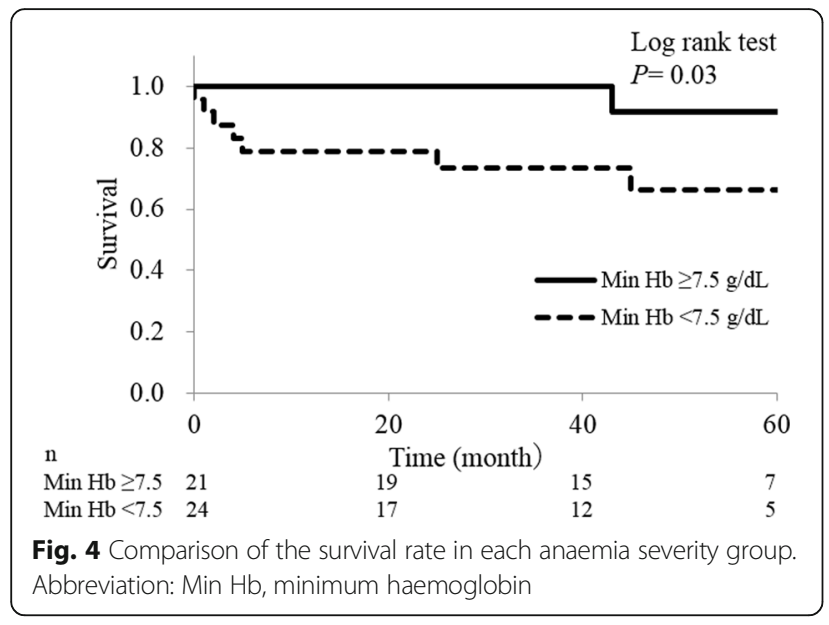

autoimmune inflammatory diseases. The previous studies reported that the prevalence of anaemia was $33-59 \%$ in patients with rheumatoid arthritis [4], 20-68\% in those with inflammatory bowel disease [5] and 38\% in those with SLE [7]. According to these studies, the causes of anaemia were multifactorial, and the main cause was ACD. In comparison, we found that anaemia was more frequent in patients with ANCA-associated renal vasculitis, and the causes of anaemia with ANCAassociated renal vasculitis were multifactorial, just as for anaemia with other autoimmune inflammatory diseases. However, the most prevalent cause was renal anaemia, not ACD. More than $90 \%$ of our patients had renal anaemia, while approximately half of the patients had ACD. A possible reason for the high prevalence of anaemia in our patients with ANCA-associated renal vasculitis may have been the interaction between renal anaemia and ACD. As described above, renal dysfunction is an important cause of ACD [8]. By contrast, inflammation is an essential cause of renal anaemia [22]. Both renal anaemia and ACD are mediated through the effects of inflammatory cytokines such as interleukin (IL)-1, IL-6, and tumour necrosis factor-alpha. Therefore, in this study, we suspected that hepcidin played a key role in the interaction between renal anaemia and ACD. Hepcidin is an acute-phase protein, which is mainly produced in the liver and secreted into the circulation. Hepcidin is the main regulator of iron metabolism, and its production is regulated by changes in the body's iron stores, inflammation, erythropoietic activity, and hypoxia [23]. It has been reported that the hepcidin level is increased in CKD patients, possibly due to increased production and/or reduced renal clearance $[24,25]$. Hepcidin is also an acute-phase reactant induced by inflammation. We therefore expected the hepcidin concentration to be increased in our patients with ANCA-associated renal vasculitis due to both renal dysfunction and inflammation. However, in this cohort, the hepcidin-25 concentration was not significantly related to anaemia severity, renal dysfunction, or other inflammatory findings. In patients with ANCAassociated renal vasculitis, there may be a more complex relationship among various factors that influence hepcidin levels, including iron, inflammation, reduced renal clearance, and anaemia severity [26]. Additionally, the measurement of the serum hepcidin-25 concentration was performed in only a limited number of patients.

Next, we addressed the reason for the high prevalence of renal anaemia and the influence of renal anaemia on the severity of anaemia in our patients with ANCAassociated renal vasculitis. McClellan et al. [15] reported that the prevalence of anaemia increased as the level of kidney function decreased. For example, the percentage of patients with haemoglobin $\leq 12 \mathrm{~g} / \mathrm{dL}$ increased from $26.7 \%$ to $75.5 \%$ as the glomerular filtration rate decreased from $\geq 60 \mathrm{~mL} / \mathrm{min} / 1.73 \mathrm{~m}^{2}$ to $<15 \mathrm{~mL} / \mathrm{min} /$ $1.73 \mathrm{~m}^{2}$. In our cohort, all patients had renal involvement, and the median eGFR was $15.3 \mathrm{~mL} / \mathrm{min} / 1.73 \mathrm{~m}^{2}$. Therefore, advanced renal dysfunction with ANCAassociated renal vasculitis corresponded to a high prevalence of renal anaemia and anaemia severity. We also performed a review of the literature to examine how renal anaemia affects anaemia severity in patients with ANCA-associated vasculitis (Table 3). Several previous studies have reported an association between renal dysfunction and anaemia severity. However, anaemia severity was relatively mild in the studies that included patients without renal involvement-that is, in patients with preserved renal function $[2,3,27]$. On the other hand, anaemia severity was relatively advanced in the ANCA-associated renal vasculitis cohorts [28-30]. Moreover, there may be a tendency for the severity of anaemia to progress as the level of kidney function decreases. As a result, we can conclude that the causes of anaemia with ANCA-associated renal vasculitis are multifactorial, and that while renal anaemia is easily missed, it is the most frequent and influential cause of anaemia in patients with ANCA-associated renal vasculitis.

Next, we investigated the mechanism of renal anaemia in ANCA-associated renal vasculitis patients. Our study of the histopathological findings demonstrated that renal interstitial damage is associated with anaemia severity. Some recent studies investigated the association between anaemia and biopsy-proven interstitial lesions of diabetic nephropathy [19], or between anaemia and posttransplant nephropathy [20]. Based on the findings of these previous studies and our present investigation, it is possible to propose several mechanisms by which interstitial damage could influence anaemia. One such mechanism is a reduction in the production of erythropoietin resulting from a decrease in erythropoietin-producing cells due to interstitial damage. Recent basic science 
Table 3 Association of renal dysfunction and anaemia severity in patients with ANCA-associated vasculitis

\begin{tabular}{|c|c|c|c|c|c|c|}
\hline Author & Disorder & $\begin{array}{l}\text { Patient } \\
\text { number }\end{array}$ & Age (years) & $\begin{array}{l}\text { Patients with renal } \\
\text { involvement (\%) }\end{array}$ & $\begin{array}{l}\text { Serum creatinine } \\
(\mathrm{mg} / \mathrm{dL})\end{array}$ & $\begin{array}{l}\text { Haemoglobin } \\
(\mathrm{g} / \mathrm{dL})\end{array}$ \\
\hline Riegersperger et al. [3] & GPA (remission status) & 36 & $58 \pm 15$ & $\begin{array}{l}42 \% \text { had pauci-immune } \\
\text { crescentic glomerulonephritis }\end{array}$ & $\begin{array}{l}\text { (eGFR } 40.6 \pm 21.4 \\
\left.\mathrm{ml} / \mathrm{min} / 1.73 \mathrm{~m}^{2}\right)\end{array}$ & $13.0 \pm 2.1$ \\
\hline Hoffman et al. [2] & GPA & 158 & $\begin{array}{l}41 \text { (range, } \\
9-78 \text { ) }\end{array}$ & 77 & not available & $\begin{array}{l}11.1 \text { (range, } \\
5.0-15.1)\end{array}$ \\
\hline Flossmann et al. [27] & ANCA-associated vasculitis & 535 & $61(49-69)$ & not available & $2.3(1.1-5.6)$ & $9.8(8.6-11.5)$ \\
\hline Crnogorac et al. [28] & ANCA-associated vasculitis & 81 & $61(50-68)$ & 100 & $3.6(2.3-6.0)$ & $9.8(8.8-11.7)$ \\
\hline Andreiana et al. [29] & ANCA-associated vasculitis & 75 & $60(53-68)$ & 100 & $5.0(3.4-7.9)$ & $8.5(7.5-9.8)$ \\
\hline Pu et al. [30] & ANCA-associated vasculitis & 123 & $62 \pm 12$ & 100 & $5.0 \pm 3.8$ & $8.3 \pm 2.1$ \\
\hline The present study & ANCA-associated renal vasculitis & 45 & $71 \pm 7.8$ & 100 & 3.2 (range, $1.0-11.7$ ) & $7.5 \pm 1.3$ \\
\hline
\end{tabular}

Values are shown as the median (interquartile range) or mean $\pm \mathrm{SD}$ if not otherwise specified. Abbreviations: GPA Granulomatosis with polyangiitis, ANCA Antineutrophil cytoplasmic antibody, eGFR Estimated glomerular filtration rate

studies have suggested that renal interstitial fibroblasts produce erythropoietin in response to hypoxia or anaemia [31]. Therefore, the progression of interstitial damage could lead to the development of anaemia, resulting in erythropoietin deficiency. However, in this study, there was no significant relationship between the area of interstitial damage and the serum erythropoietin concentration. Nonetheless, this discrepancy may be attributable to study limitations. That is, we measured the serum erythropoietin concentration only in a limited number of patients. In addition, we could not perform renal biopsies in all patients.

Whether anaemia with ANCA-associated renal vasculitis influences the renal and life prognoses must also be addressed. As described above, several studies have demonstrated that anaemia is a risk factor for shortened lifespan and/or increased renal dysfunction [11, 12]. Similarly, the present data demonstrated that anaemia severity was associated with life prognosis in our patients with ANCA-associated renal vasculitis. On the other hand, eGFR was also significantly different between the groups at the time of minimum eGFR, and the lower haemoglobin group tended to have a lower eGFR. Therefore, our results underscore that the severity of anaemia has an impact on renal and life prognoses. In general, the administration of ESAs is beneficial in patients with renal anaemia [32, 33], and the use of ESAs may be a treatment option for patients with ACD [8]. Unfortunately, although renal anaemia was diagnosed in 35 patients in this cohort, ESAs were used in only 16 of the $35(46 \%)$. There is a possibility that the treatment for anaemia itself would lead to an improvement in the prognosis of patients with ANCA-associated renal vasculitis. In the future, therefore, it will be important to investigate the efficacy of earlier treatment initiation for anaemia, the optimal timing of anaemia intervention and the effectiveness of ESAs therapy.

Finally, our study has several limitations. First, this study was a retrospective investigation of a small cohort at a single centre, and our results therefore cannot be generalized without further investigation. Second, when our patients with ANCA-associated renal vasculitis had both renal anaemia and ACD, it was difficult to clearly distinguish between them. Third, as described above, we could not analyse patients with ANCA-associated vasculitis without renal involvement. Despite these limitations, the present study provided the first investigation of the pathogenesis of anaemia with ANCA-associated renal vasculitis and the impact of anaemia on prognosis. It is hoped that our findings will inspire additional research in a larger cohort.

\section{Conclusions}

We demonstrated a high prevalence of anaemia in a cohort of patients with ANCA-associated renal vasculitis. A possible reason for the high prevalence of anaemia in these patients was the interaction between renal anaemia and ACD. The severity of anaemia was associated with the degree of renal dysfunction and life prognosis.

\section{Abbreviations}

ACD: Anaemia of chronic disease; ANCA: Antineutrophil cytoplasmic antibody; CKDChronic kidney disease; eGFR: Estimated glomerular filtration rate; ELISA: Enzyme-linked immunosorbent assay; ESAs: Erythropoiesisstimulating agents; GPA: Granulomatosis with polyangitis; IL: Interleukin; min Hb: Minimum haemoglobin; SD: Standard deviation; SLE: Systemic lupus erythematosus

\section{Acknowledgements}

We thank Ms. Hideko Sakurai, Ms. Rie Kikkou, and Ms. Mikie Daigo (University of Tsukuba) for their technical support

\section{Funding}

This work was supported by a Grant for a Pathophysiological Research Conference in Chronic Kidney Disease from The Kidney Foundation of Japan (Joichi Usui in 2014), a Grant-in-Aid for Intractable Renal Diseases Research, a Grant for Research on Rare and Intractable Diseases, and Health and Labour Sciences Research Grants from the Ministry of Health, Labour and Welfare of Japan.

Availability of data and materials

The datasets used and/or analysed during the current study are available from the corresponding author on reasonable request. 


\section{Authors' contributions}

$\mathrm{JU}$ and $\mathrm{KY}$ designed the study. JU and MN made the histological diagnoses. TK, JU and SK collected the clinical data. TK, JU, SK, RT, El, HK, NM, CS and KY performed the data analysis and wrote the manuscript. All authors approved the final manuscript and data.

\section{Ethics approval and consent to participate}

This research complied with the Declaration of Helsinki and was approved by the Ethics Committee of University of Tsukuba Hospital (H20-273, H24169 and H26-175). All participants provided informed consent to participate in the study as required by the Institutional Review Board (H2O-273). An announcement of this study was simultaneously posted at the outpatient clinic of our institute.

\section{Consent for publication}

Not applicable.

\section{Competing interests}

None of the authors had competing interests to declare.

\section{Publisher's Note}

Springer Nature remains neutral with regard to jurisdictional claims in published maps and institutional affiliations.

\section{Author details}

'Department of Nephrology, Faculty of Medicine, University of Tsukuba, 1-1-1 Tennodai, Tsukuba, Ibaraki 305-8575, Japan. ${ }^{2}$ Department of Pathology, Faculty of Medicine, University of Tsukuba, Tsukuba, Ibaraki, Japan.

\section{Received: 15 June 2017 Accepted: 14 November 2017}

\section{Published online: 25 November 2017}

\section{References}

1. Jennette JC, Falk RJ. Small-Vessel Vasculitis. N Engl J Med. 1997;337(21): $1512-23$.

2. Hoffman GS, Kerr GS, Leavitt RY, Hallahan CW, Lebovics RS, Travis WD, Rottem M, Fauci AS. Wegener granulomatosis: an analysis of 158 patients. Ann Intern Med. 1992;116(6):488-98.

3. Riegersperger M, Sengoelge G, Köller M, Grossmann N, Benesch T, SunderPlassmann G. Anemia in patients with Wegener's granulomatosis. Clin Nephrol. 2007;67(3):149-56.

4. Wilson A, Yu HT, Goodnough LT, Nissenson AR. Prevalence and outcomes of anemia in rheumatoid arthritis: a systematic review of the literature. Am J Med. 2004;116(Suppl 7A):50S-7S.

5. Nielsen $\mathrm{OH}$, Ainsworth $\mathrm{M}$, Coskun $\mathrm{M}$, Weiss $\mathrm{G}$. Management of IronDeficiency Anemia in inflammatory bowel disease: a systematic review. Medicine (Baltimore). 2015;94(23):e963.

6. Bergamaschi G, Di Sabatino A, Albertini R, Ardizzone S, Biancheri P, Bonetti E, Cassinotti A, Cazzola P, Markopoulos K, Massari A, et al. Prevalence and pathogenesis of anemia in inflammatory bowel disease. Influence of antitumor necrosis factor-alpha treatment. Haematologica. 2010;95(2):199-205.

7. Voulgarelis M, Kokori SI, loannidis JP, Tzioufas AG, Kyriaki D, Moutsopoulos HM. Anaemia in systemic lupus erythematosus: aetiological profile and the role of erythropoietin. Ann Rheum Dis. 2000;59(3):217-22.

8. Weiss G, Goodnough LT. Anemia of chronic disease. N Engl J Med. 2005; 352(10):1011-23

9. Culleton BF, Manns BJ, Zhang J, Tonelli M, Klarenbach S, Hemmelgarn BR. Impact of anemia on hospitalization and mortality in older adults. Blood. 2006:107(10):3841-6.

10. Go AS, Yang J, Ackerson LM, Lepper K, Robbins S, Massie BM, Shlipak MG. Hemoglobin level, chronic kidney disease, and the risks of death and hospitalization in adults with chronic heart failure: the anemia in chronic heart failure: outcomes and resource utilization (ANCHOR) study. Circulation. 2006;113(23):2713-23.

11. Mohanram A, Zhang Z, Shahinfar S, Keane WF, Brenner BM, Toto RD. Anemia and end-stage renal disease in patients with type 2 diabetes and nephropathy. Kidney Int. 2004;66(3):1131-8.

12. Iseki K, Ikemiya Y, Iseki C, Takishita S. Haematocrit and the risk of developing end-stage renal disease. Nephrol Dial Transplant. 2003;18(5):899-905.

13. Nutritional anaemias. Report of a WHO scientific group. World Health Organ Tech Rep Ser 1968, 405:5-37.
14. Artunc F, Risler T. Serum erythropoietin concentrations and responses to anaemia in patients with or without chronic kidney disease. Nephrol Dial Transplant. 2007;22(10):2900-8,

15. McClellan W, Aronoff SL, Bolton WK, Hood S, Lorber DL, Tang KL, Tse TF, Wasserman B, Leiserowitz M. The prevalence of anemia in patients with chronic kidney disease. Curr Med Res Opin. 2004;20(9):1501-10.

16. Peters HP, Rumjon A, Bansal SS, Laarakkers CM, van den Brand JA, Sarafidis P, Musto R, Malyszko J, Swinkels DW, Wetzels JF, et al. Intraindividual variability of serum hepcidin-25 in haemodialysis patients using mass spectrometry and ELISA. Nephrol Dial Transplant. 2012; 27(10):3923-9.

17. Azab SF, Akeel NE, Abdalhady MA, Elhewala AA, Ali AS, Amin EK, Sarhan DT, Almalky MA, Elhindawy EM, Salam MM, et al. Serum Hepcidin levels in childhood-onset ischemic stroke: a case-control study. Medicine (Baltimore). 2016:95(9):e2921.

18. Berden AE, Ferrario F, Hagen EC, Jayne DR, Jennette JC, Joh K, Neumann I, Noel LH, Pusey CD, Waldherr R, et al. Histopathologic classification of ANCAassociated glomerulonephritis. J Am Soc Nephrol. 2010;21(10):1628-36.

19. Mise K, Hoshino J, Ueno T, Imafuku A, Kawada M, Sumida K, Hiramatsu R, Hasegawa E, Yamanouchi M, Hayami N, et al. Impact of tubulointerstitial lesions on anaemia in patients with biopsy-proven diabetic nephropathy. Diabet Med. 2015:32(4):546-55.

20. Tsuchimoto A, Masutani K, Haruyama N, Nagata M, Noguchi H, Okabe Y, Kitada H, Tanaka M, Tsuruya K, Kitazono T. Renal interstitial fibrosis in 0-hour biopsy as a predictor of post-transplant anemia. Am J Nephrol. 2013;38(4): 267-74.

21. Okabayashi Y, Tsuboi N, Sasaki T, Haruhara K, Kanzaki G, Koike K, Miyazaki Y, Kawamura T, Ogura M, Yokoo T. Glomerulopathy associated with moderate obesity. Kidney International Reports. 2016;1 (4):250-5.

22. Stenvinkel P. The role of inflammation in the anaemia of end-stage renal disease. Nephrol Dial Transplant. 2001;16(Suppl 7):36-40.

23. Nemeth E, Tuttle MS, Powelson J, Vaughn MB, Donovan A, Ward DM, Ganz T. Kaplan J. Hepcidin regulates cellular iron efflux by binding to ferroportin and inducing its internalization. Science. 2004;306(5704):2090-3.

24. Zaritsky J, Young B, Wang HJ, Westerman M, Olbina G, Nemeth E, Ganz T, Rivera S, Nissenson AR, Salusky IB. Hepcidin-a potential novel biomarker for iron status in chronic kidney disease. Clin J Am Soc Nephrol. 2009:4(6): 1051-6.

25. Ashby DR, Gale DP, Busbridge M, Murphy KG, Duncan ND, Cairns TD, Taube DH, Bloom SR, Tam FW, Chapman RS, et al. Plasma hepcidin levels are elevated but responsive to erythropoietin therapy in renal disease. Kidney Int. 2009;75(9):976-81

26. Malyszko J, Mysliwiec M. Hepcidin in anemia and inflammation in chronic kidney disease. Kidney Blood Press Res. 2007:30(1):15-30.

27. Flossmann O, Berden A, de Groot K, Hagen C, Harper L, Heijl C, Höglund P, Jayne D, Luqmani R, Mahr A, et al. Long-term patient survival in ANCAassociated vasculitis. Ann Rheum Dis. 2011;70(3):488-94.

28. Crnogorac M, Horvatic I, Toric L, Galesic Ljubanovic D, Tisljar M, Galesic K. Clinical, serological and histological determinants of patient and renal outcome in ANCA-associated vasculitis with renal involvement: an analysis from a referral centre. Int Urol Nephrol. 2017;49(8):1419-31.

29. Andreiana I, Stancu S, Avram A, Taran L, Mircescu G. ANCA positive crescentic glomerulonephritis outcome in a central east European cohort: a retrospective study. BMC Nephrol. 2015;16:90.

30. Pu L, Li GS, Zou YR, Zhang P. Wang L. Clinical predictors of outcome in patients with anti-neutrophil Cytoplasmic autoantibody-related rena Vasculitis: experiences from a single-center. Chin Med J. 2017:130(8): 899-905.

31. Asada N, Takase M, Nakamura J, Oguchi A, Asada M, Suzuki N, Yamamura K, Nagoshi N, Shibata S, Rao TN, et al. Dysfunction of fibroblasts of extrarenal origin underlies renal fibrosis and renal anemia in mice. J Clin Invest. 2011; 121(10):3981-90

32. Gouva C, Nikolopoulos P, loannidis JP, Siamopoulos KC. Treating anemia early in renal failure patients slows the decline of renal function: a randomized controlled trial. Kidney Int. 2004;66(2):753-60.

33. Tsubakihara Y, Gejyo F, Nishi S, lino Y, Watanabe Y, Suzuki M, Saito A, Akiba T, Hirakata H, Akizawa T. High target hemoglobin with erythropoiesis-stimulating agents has advantages in the renal function of non-dialysis chronic kidney disease patients. Ther Apher Dial. 2012;16(6):529-40. 